\title{
Distinct Indiscernibles and the Bundle Theory
}

\author{
DEAN W. ZIMMERMAN
}

A: Like Locke, you think an object must be something more than its properties. So you posit a mysterious "substratum", an unreachable "kernel" that bears properties but is not itself a property. This is metaphysics at its most gratuitous and pernicious. All we observe or detect are the properties of things, and a particular substance is nothing more than a bundle of properties.

$B$ : So you say. But remember Max Black's description of a world containing nothing but two intrinsically indiscernible spheres, at some distance from one another (Black, 1952)? You have yet to satisfy me that your bundle theory of substance is compatible with the possibility of such a world.

A: I must admit, Black's world had me worried for a time. But it now seems clear to me that the possibility he describes poses no real threat to the bundle theory.

$B$ : How so? The spheres have to be bundles of the very same universals; and they can't be distinguished by their relations to one another, either. Throwing in relations to different places won't help, since the places in question are indiscernible, too. If you posit distinct but indiscernible places, doesn't this amount to the recognition of things that are something more than mere bundles of universals? The only way out is to deny that Black's world is really possible. But I know you too well to think that you'll take that route; you're not one of these "modally-challenged" philosophers, unable to recognize a possibility when they see one.

A: Ah, but there is another way out. ${ }^{1}$ In order to see it, you must first recall that the universals I' $m$ bundling into substances are not, of course, Platonic entities existing outside of space and time somewhere. They're "immanent universals", located right where and when their instances are.

$B$ : Oh, you're bundling tropes, particular instances of universals, which can differ solo numero. That will solve the problem-but it's cheating, from the point of view of the traditional bundle theory. You've

${ }^{1}$ This response to Black's spheres is given by O'Leary-Hawthorne (1995). 
brought brute particularity back into your metaphysical picture; you're not bundling real universals any longer.

A: No, immanent universals aren't tropes; they're real universals, wholly present in each instance. They differ from Platonic universals only in being spatiotemporally located.

$B$ : So the blueness on the surface of one sphere, say, is numerically identical with the blueness on the surface of another sphere of exactly the same hue?

A: Right. And you're probably beginning to see how I'll answer Black. It's quite simple really: the situation he describes is surely possible; but it is a world in which a single bundle of universals - the universals of solidity, mass, shape, color, etc. collocated in one of the spheresis at some distance from itself.

$B$ : “At some distance from itself"! Surely that's a contradiction.

$A$ : If so, then the very idea of an immanent universal is contradictory. An immanent universal will routinely be "at some distance from itself", in the sense that it is wholly present in more than one place. If you grant me immanent universals, then you must allow that my redescription of the sphere-world is consistent.

$B$ : But it is a redescription, is it not? Black's world contains two spheres. But your bi-located bundle is just one thing that shows up in two places.

A: Granted, Black says his world has two distinct spheres in it; but to insist on including this as part of the description of the world is to beg the question against the bundle theorist. I submit that the possibility Black's story illustrates is simply this: a symmetrical universe, a world in which the pattern of properties exemplified on one side of a certain plane is precisely mirrored on the opposite side. You want to insist that, in addition, the objects on the one side of the plane of symmetry are numerically distinct from those on the other. But it is not at all clear to me that that is possible.

$B$ : Well, let me try to make it clear to you. Suppose that nothing exists save two electrons - or, if you like, that the same bundle of electronish properties appears on opposite sides of a symmetrical universe. Suppose further that electrons obey indeterministic laws. In that case, even though the electron on the one side is now indiscernible from the one on the other, it remains possible that differences will emerge later on-in other words, it is possible that this one should have a future differing from that one. And even in the case of an eternally symmetrical, two-electron universe in which differences never emerge, such differences were nonetheless possible-both logically or metaphysically possible, and physically or causally possible, too. But you cannot 
recognize this possibility: on your view the "electrons" must really be a single bundle, and so nothing could be true of the one but false of the other.

A: I fear we may have reached an impasse; for this objection of yours depends upon the resolution of another long-standing quarrel between us: namely, how best to analyze modal statements.

$B$ : You're still peddling your "counterpart theory", I imagine?

A: Naturally. And your argument tacitly assumes the falsity of a counterpart-theoretic approach to de re modal ascriptions. According to my counterpart semantics, the possibilities open to a given object are not determined by what it does in other possible worlds, but rather by what its counterparts do in other possible worlds-and a counterpart is similar to, but not identical with, the original object. I can simply adopt a semantics for the statement "The (so-called) 'two' electrons could have diverged" that ascribes truth to this statement just in case the single bi-located electron-bundle in the world you described has two counterparts inhabiting some other world, and the two counterparts differ there in the required ways.

$B$ : Of course you know what I think of a counterpart semantics for modal ascriptions. But even if I grant you that, I don't see how it helps. The world you describe, in which the bi-located bundle has two counterparts, allows you to say that the one bi-located electron could have been two electrons. But something more is possible in the world I described: the electron on the one side could have developed differently while the one on the other side did not. But if "they" are identical, "they" must have the same counterparts in every possible situation-and so there's no possible world in which the one but not the other has a counterpart with a particular future.

A: Perhaps counterpart theory by itself doesn't dissolve the problem entirely. But the more I think about this alleged possibility, the less troubled I am by it. Who says it has to be possible for the "one" electron to change its state without the "other" doing so as well? I say they're the same bundle; so when I think about it, I have a hard time even imagining what you're talking about.

$B$ : Just another case of philosophical theory corrupting modal judgment. Let me try one last time to help you grasp the eminently possible situation I'm thinking about: there are just two electrons, they are and remain exactly alike, and the behavior of each one evolves independently of the other. Think of them as being far apart, and moving away from each other at a constant rate. Now, given that each behaves in accordance with slightly indeterministic laws, there are ways in which each one could come to differ from the other in the future, although in 
fact they remain synchronized. But there is no way you can allow for the possibility that one does something that the other does not. You have to say the particles are modally linked; that there is no possible world in which they differ. It follows from your view that every pair of indiscernible particles must behave in a way analogous to bosons: however far apart they are, if the one changes its state the other one must as well.

A: I'll admit that there is something a little bit odd about ruling out the alleged possibilities you describe. But why can't I just hold a bundle theory for the objects in the actual world? After all, it is only in these bizarrely symmetrical universes that problems arise.

$B$ : So you want to restrict your thesis to just those worlds that lack distinct indiscernibles?

$A$ : Something like that, yes.

B: Doesn't the ad hoc nature of the restriction bother you? Pick a couple of almost indiscernible particles in the actual world. Couldn't they (or at least a pair just like them) exist in a world by themselves, where they remain distinct because of some small change which the one undergoes but the other does not?

A: As long as they remain distinct bundles of universals, I can't see that your earlier objections have any foothold.

$B$ : Not in that world. But we are only a small step from another world where the one fails to undergo this little change. Suddenly, you have to give up your metaphysics of pure bundles, and posit underlying substrata or some such things. Surely it is implausible to suppose that a tiny change in the global distribution of intrinsic properties would require a radical change in ontology! ${ }^{2}$

A: That does sound a bit unsatisfactory. But your objections have begun to seem less and less pressing to me. Perhaps there is really no need to retreat to a contingent version of the bundle theory. Call me "modally challenged" if you like, but I'm no longer at all sure that the two independently evolving but indiscernible electrons you describe really are possible; it's not obvious to me that, given that the "two" really are indiscernible, one of them could behave in a certain way while the other does not.

$B$ : Well, it would be obvious to you, if you weren't such a devotee of the bundle theory.

Department of Philosophy University of Notre Dame

Notre Dame, Indiana 46556

dean.w.zimmerman.4@nd.edu

DEAN W. ZIMMERMAN

${ }^{2}$ Cf. Adams (1979); and Armstrong (1989, pp. 64-70). 
Distinct Indiscernibles and the Bundle Theory 309

\section{REFERENCES}

Adams, R. M. 1979: "Primitive Thisness and Primitive Identity". Journal of Philosophy, 76, pp. 5-26.

Armstrong, D. M. 1989: Universals: An Opinionated Introduction. Boulder, Colorado: Westview Press.

Black, M. 1952: "The Identity of Indiscernibles". Mind, 61, pp. 152-64.

O'Leary-Hawthorne, J. 1995: "The Bundle Theory of Substance and the Identity of Indiscernibles". Analysis, 55, pp. 191-6. 
310 Dean W. Zimmerman 